\title{
Analisis Rasio Keuangan untuk Menilai Kinerja Hotel Ciater Spa \& Resort, Subang
}

\author{
Pudin Saepudin*1, Syaeful Muslim² \\ Sekolah Tinggi Pariwisata Bandung, Indonesia ${ }^{1,2}$ \\ Email: pus@stp-bandung.ac.id
}

\begin{abstract}
Financial ratio analysis of a company is one of the financial performance assessments that are very useful to management in making a plan for both short term and long term. The purpose of this research is to evaluate the implementation of financial statement analysis carried out by Hotel Ciater Spa \& Resort in 2013 and 2014. The research method used is descriptive method. The results of the analysis show that the level of liquidity ratios, solvency, and operational is quite high, while the ratio of profitability has. fluctuated and the ratio of the activity has not been fully effective..
\end{abstract}

Keywords: financial ratio analysis, performance, Hotel Ciater Spa \& Resort.

\begin{abstract}
Abstrak
Analisis rasio keuangan suatu perusahaan adalah salah satu penilaian kinerja keuangan yang sangat berguna bagi manajemen dalam membuat rencana untuk jangka pendek dan jangka panjang. Tujuan dari penelitian ini adalah untuk mengevaluasi pelaksanaan analisis laporan keuangan yang dilakukan oleh Hotel Ciater Spa \& Resort pada tahun 2013 dan 2014. Metode penelitian yang digunakan adalah metode deskriptif. Hasil analisis menunjukkan bahwa tingkat rasio likuiditas, solvabilitas, dan operasional cukup tinggi, sedangkan rasio profitabilitas sudah. berfluktuasi dan rasio kegiatan belum sepenuhnya efektif..
\end{abstract}

Kata Kunci: analisis rasio keuangan, kinerja, Hotel Ciater Spa \& Resort.

\section{A. PENDAHULUAN}

Tingkat persaingan dunia usaha saat ini semakin hari semakin ketat sehingga perusahaan dituntut untuk menilai perusahaan. Salah satu penilaian yang penting dilakukan oleh manajemen perusahaan adalah penilaian kinerja atau prestasi perusahaan dengan melihat prestasi keuangan perusahaan tersebut. Penilaian kondisi keuangan dan perkembangan perusahaan dapat dilihat dari laporan keuangannya yang akan berguna bagi manajemen dalam membuat perencanaan baik jangka pendek maupun jangka panjang serta keputusan ekonomi lainnya bagi kemajuan perusahaan.

Definisi laporan keuangan menurut Ikatan Akuntan Indonesia dalam Standar Akuntansi Keuangan PSAK No. 1 (2004:4) bahwa laporan keuangan merupakan laporan periodik yang disusun menurut prinsip-prinsip akuntansi yang diterima secara umum tentang status keuangan dari individu, asosiasi atau organisasi bisnis yang terdiri dari neraca, laporan laba rugi, laporan perubahan ekuitas, laporan arus kas dan catatan atas laporan keuangan.

Definisi analisis laporan keuangan menurut Sofyan Syafri Harahap (2002:93) adalah menguraikan pos-pos laporan keuangan menjadi unit informasi yang lebih kecil dan melihat hubungannya yang bersifat signifikan atau yang mempunyai makna antara satu dengan yang lain baik antara data kuantitatif maupun

* Corresponding author

Received: August 03, 2019; Revised: October 05, 2019; Accepted: December 11, 2019 
data non kuantitatif dengan tujuan untuk mengctahui kondisi keuangan lebih dalam yang sangat penting dalam proses menghasilkan keputusan yang tepat.

Menurut Ivl Faisal Abdullah (2005:123) berdasarkan tekniknya, analisis laporan keuangan dapat dibedakan menjadi:

a) Analisis perbandingan laporan keuangan

b) Analisis trend (tendensi posisi)

c) Analisis persentasc per komponen (common size)

d) Analisis sumber dan penggunaan modal kerja

e) Analisis sumber dan penggunaan kas

f) Analisis rasio keuangan

g) Analisis perubahan laba kotor

h) Analisis break even

Analisis rasio keuangan merupakan salah satu metode atau teknik analisis laporan keuangan yang sering digunakan oleh para pimpinan di suatu perusahaan. Rasio keuangan ini sendiri berarti angka yang mewakili nilai dari salah satu variable keuangan terhadap variabel keuangan yang lain.

Menurut Ridwan, Sundjaja dan Barlian (2002:104) terdapat dua cara dalam menginterpretasikan rasio keuangan yaitu:

a) Analisis rasio yang dibandingkan dengan perusahaan lain

b) Analisis rasio yang dibandingkan dalam perusahaan sendiri secara berkala dari waktu ke waktu.

Jenis-jenis rasio keuangan yang digunakan dalam bidang industri hospitaliti seperti hotel dan usaha pariwisata lainnya menurut Raymond S. Schmidgall (2002:206- 207) adalah liquidity, solvency, activity, profitability, and operatings.

Kinerja keuangan sebuah perusahaan dijelaskan olch Agnes Sawir (2005:1) sebagai ukuran mengcnai sebcrapa jauh perusahaan-perusahaan berada dari batas normal agar perusahaan dapat dikatakan sehat dan berjalan baik sehingga dapat memenuhi kewajibannya dan menghasilkan keuntungan di masa yang akan datang. Adapun ruinusan masalah dalam penelitian ini adalah bagaimana rasio-rasio keuangan dapat digunakan untuk menilai kinerja Hotel Ciater Spa \& Resort pada periode waktu tahun 2013 dan 2014.

Tujuan penelitian ini adalah untuk mengetahui pelaksanaan analisis laporan keuangan yang dilakukan oleh Hotel Ciater Spa \& Resort dan untuk mengetahui analisis rasio keuangan dalam mengevaluasi kinerja Hotel Ciater Spa \& Resort pada tahun 2013 dan 2014 karena sejauh ini mereka hanya melakukan analisis sederhana yaitu analisis vertikal dan horisontal.

\section{B. METODE PENELITIAN}

Teknik penelitian yang dilakukan penulis bersifat studi komparatif karena membandingkan data keuangan Hotel Ciater Spa \& resort tahun 2013 dan 2014. Sedangkan metode penelitian yang digunakan adalah metode deskriptif, metode ini menurut Sugiyono (2004:11) adalah metode yang berusaha mengumpulkan data yang sesuai dengan keadaan yang sebenarnya, menyajikan dan menganalisisnya sehingga dapat memberikan perbandingan yang cukup jelas mengenai objek yang diteliti yang kemudian dapat ditarik suatu kesimpulan. Adapun sumber data yang digunakan dalam penelitian ini adalah data primer yaitu wawancara terhadap chief accountant dan general manager Hotel Ciater Spa \& Resort serta observasi dan data sekunder yaitu berupa data - data terkait yang diperoleh melalui dokumen penelitian yang berasal dari hasil kajian literatur/kajian pustaka serta hasil penelitan yang berkaitan dengan objek masalah yang sama. 


\section{HASIL DAN ANALISIS}

\section{Rasio Likuiditas (Liquidity Ratio)}

Tabel 1 Rasio Likuiditas (Liquidity Ratio)

\begin{tabular}{|c|c|c|c|}
\hline Tahun & Current Assets & Current Liabilities & Current Ratio \\
\hline 2013 & $\operatorname{Rp} 3,470,294,443$ & $\mathrm{Rp} 704,166,542$ & 4.93 \\
\hline 2014 & Rp 5,074,987,174 & Rp 588,117,071 & 8.63 \\
\hline \multicolumn{4}{|c|}{ Acid-Test Ratio } \\
\hline Tahun & $\begin{array}{c}\text { Cash, Marketable } \\
\text { Securities Receivables }\end{array}$ & Current Liabilities & Current Ratio \\
\hline 2013 & $\operatorname{Rp} 2,691,366,036$ & Rp 704,166,542 & 3.82 \\
\hline 2014 & $\operatorname{Rp~3,673,283,145~}$ & Rp 588,117,071 & 6.25 \\
\hline \multicolumn{4}{|c|}{ Average Accounts Receivable (AR) } \\
\hline Tahun & Beginning AR & Ending $A R$ & Average AR \\
\hline 2013 & Rp 1,373,952,253 & $\operatorname{Rp} 2,220,681,567$ & Rp 1,797,316,910 \\
\hline 2014 & $\operatorname{Rp} 2,220,681,567$ & Rp 2,938,228,672 & Rp 2,579,455,120 \\
\hline \multicolumn{4}{|c|}{ Accounts Receivable (AR) Turnover } \\
\hline Tahun & Total Revenue & Average $A R$ & AR Turnover \\
\hline 2013 & Rp 16,140,873,176 & Rp 1,797,316,910 & 9 \\
\hline 2014 & Rp 15,646,659,894 & Rp 2,579,455,120 & 6 \\
\hline \multicolumn{4}{|c|}{ Average Collection Period } \\
\hline Tahun & Total Days & Average $A R$ & $\begin{array}{c}\text { Average Collection } \\
\text { Period }\end{array}$ \\
\hline 2013 & 365 & 9 & 41 \\
\hline 2014 & 365 & 6 & 60 \\
\hline
\end{tabular}

Berdasarkan tabel 1 dapat dipahami bahwa pada tahun 2013 untuk setiap nilai Rp 1.- hutang lancar, akan ditutup oleh $\mathrm{Rp}$ 4,93.- harta lancar dan tahun 2014 untuk setiap nilai Rp 1.- hutang lancar, akan ditutup oleh Rp 8,63.- harta lancar. Hal ini berarti harta lancar (current assets) Hotel Ciater Spa \& Resort masih mampu untuk menutupi hutang-hutang lancarnnya (current liabilities) sebesar 4,93 kali untuk tahun 2013 dan 8,63 kali untuk tahun 2014 atau terjadi kenaikan kemampuan yang cukup berarti. Selain itu current assets hotel Ciater Spa \& Resort selain persediaan (inventories) dan biaya dibayar dimuka (prepaid expenses) mampu untuk menutupi current liability sebesar 3,82 kali pada tahun 2013 dan 6,25 kali pada tahun 2014. Hal ini menunjukkan likuditas dari quick assets yang dimiliki oleh Hotel Ciater Spa \& Resort cukup tinggi untuk membayar hutang-hutang lancarnya seperti hutang ke pemasok (supplier) serta mengalami kenaikan dari tahun ke tahunnya.

Rasio perputaran piutang yang terjadi di Hotel Ciater Spa \& Resort menunjukkan data tahun 2013 sebesar 9 kali dalam setahun (41 hari sekali) sedangkan tahun 2014 sebesar 6 kali (60 hari sekali). Hal ini menunjukkan bahwa terjadi penurunan kualitas penagihan piutang dari 32 hari sekali (1 bulan sekali) menjadi 60 hari sekali (dua bulan sekali) pada tahun 2014. Bila hal ini dibiarkan akan menjadi tidak balk bagi kondisi cash flow perusahaan karena semakin lama pembayaran piutang maka semakin buruk cash flow perusahaan, sebaliknya semakin cepat pembayaran piutang maka semakin sehat cash flow perusahaan.

100 Jurnal Kepariwisataan: Destinasi, Hospitalitas dan Perjalanan, Volume 3 Nomor 2, 2019: 98-105 


\section{Rasio Solvabilitas (Solvency Ratio)}

Tabel 2 Rasio Solvabilitas (Solvency Ratio)

\begin{tabular}{|c|c|c|c|}
\hline Tahun & Total Assets & Total Liabilities & Solvency Ratio \\
\hline 2013 & Rp 23,136,280,259 & Rp 1,789,433,703 & 12.93 \\
\hline 2014 & Rp 23,500,567,633 & Rp 1,673,384;232 & 14.04 \\
\hline \multicolumn{4}{|c|}{ Debt-Equity Ratio } \\
\hline Tahun & Total Liabilities & Total & Debt-Equity Ratio \\
\hline 2013 & Rp 1,789,433,703 & $\operatorname{Rp} 21,346,846,556$ & 0.08 \\
\hline 2014 & Rp 1,673,384,232 & Rp 21,827,183,401 & 0.08 \\
\hline \multicolumn{4}{|c|}{ Capitalization Ratio } \\
\hline Tahun & Long-Term Debt & Owners' Equity & Capitalization Ratio \\
\hline 2013 & Rp 1,085,267,161 & Rp 21,346,846,556 & Rp 22,432,113,717 \\
\hline 2014 & Rp 1,085,267,161 & Rp 21,827,183,401 & Rp 22,912,450,562 \\
\hline \multicolumn{4}{|c|}{ Long-Tern Debt to Capitalization Ratio } \\
\hline
\end{tabular}

Tahun $\quad$ Long Ter $n$ Debt $\quad$ Capitalization Ratio

Long-TermDebtCCapitaleationRatio

\begin{tabular}{llll}
\hline 2013 & $R p 1,085,267,161$ & $R p 22,432,113,717$ & $4.84 \%$ \\
\hline 2014 & $\operatorname{Rp~1,085,267,161}$ & $\operatorname{Rp~22,912,450,562}$ & $4.74 \%$
\end{tabular}

Berdasarkan tabel 2 dapat dilihat bahwa pada tahun 2013 sebesar Rp 12,93,-harta (assets) Hotel Ciater Spa \& Resort slap untuk menutupi Rp 1,- hutang (liabiliites dan tahun 2014 sebesar Rp 14,04- harta (assets) Hotel Ciater Spa \& Resort siap untuk menutupi Rp 1,- hutang (liabiliites). Hal ini berarti harta (assets) Hotel Ciater Spa \& Resort masih mampu untuk menutupi hutang-hutangnnya (liabilities) baik hutang jangka pcndek maupun jangka panjang sebesar 12,93 kali untuk tahun 2013, dan 14,04 kali untuk tahun 2014. Kemudian untuk debt-equity ratio terlihat bahwa perbandingan komposisi hutang (liabilities) Hotel Ciater Spa \& Resort pada tahun 2013 dan 2014 nilainya sama yaitu sebesar Rp 0,08,terhadap Rp 1,- equity. Hal ini menunjukkan sedikitnya pemanfaatan hutang (liabilities) untuk operasional dan pengembalian investasi perusahaan dibandingkan dengan modal pemilik (equity).

Persentase long-ter $=m$ debt to capitalization tahun 2013 adalah 4,84\% sedangkan tahun 2014 turun menjadi 4,74\%. Walaupun nilainya relative stabil di angka $4 \%$ namun bagi pemilik hal ini kurang bagus karena pada umumnya mereka mengharapkan tingkat persentase longterm debt to capitalization yang tinggi agar tingkat pengembalian modal melalui pemanfaatan hutang jangka panjang semakin tinggi, namun bagi kreditor justru persentase long-term debt to capitalization yang kecil ini baik karena mengurangi resiko kredit macet.

\section{Rasio Aktivitas (Activity Ratio)}

Dari tabel 3 terlihat bahwa perputaran persediaan (inventory turnover) Hotel Ciater Spa \& Resort mengalami penurunan dari tahun 2013 sebesar 13 kali dalam setahun menjadi 9 kali dalam setahun pada tahun 2014. Hal ini menunjukkan semakin efektifnya penggunaan bahan baku yang menjadi bagian persediaan untuk dimanfaatkan sebesar-besarnya bagi operasional perusahaan dan semakin sedikitnya kemungkinan persediaan yang rusak atau terbuang percurna karena kadaluwarsa.

Perputaran harta tetap (fixed assets turn over) tahun 2013 dan 2014 sama yaitu 0,8 kali. Hal ini menggambarkan bahwa pemanfaatan harta tetap (fixed assets) yang dimilild oleh Hotel Ciater Spa \& 
Resort dalam menghasilkan penjualan masih belum maksimal sehingga perlu adanya kajian ulang (review) dari manajemen khusus mengenai keberadaan, kondisi, dan pemanfaatan fixed asset. Sedangkan assets turnover (perputaran harta) Hotel Ciater Spa \& Resort dari tahun 2013 dan 2014 cenderung stabil di angka 0,7 kali. Hal ini menunjukkan bahwa pemanfaatan aset Hotel Ciater Spa \& Resort baik current assets, fixed assets, maupun other assets dari tahun ke tahun masih belum efektif dalam menghasilkan penjualan.

Tabel 3 Aktivitas (Activity Ratio)

\begin{tabular}{|c|c|c|c|}
\hline Tahun & Beginning Inventory & Ending Inventory & Average Inventory \\
\hline 2013 & Rp 603,667,865 & $547,118,205$ & Rp 575,393,035 \\
\hline 2014 & Rp 547,118,205 & Rp 1,147,256,114 & Rp 847,187,160 \\
\hline \multicolumn{4}{|c|}{ Inventory Turnover- } \\
\hline Tahun & Cost of Good Sold & Average Inventory & Inventory Turnover \\
\hline 2013 & Rp 7,764,870,587 & Rp 575,393,035 & 13 \\
\hline 2014 & Rp 7,906,852,364 & Rp 847,187,160 & 9 \\
\hline
\end{tabular}

Average Fixed Assets

\begin{tabular}{c|r|r|r}
\hline Tahun & Beginning Fixed Assets & Ending Fixed Assets & Average Fixed Assets \\
\hline 2013 & $\operatorname{Rp~} 20,740,387,215$ & $\operatorname{Rp~} 19,665,985,816$ & $\operatorname{Rp} 20,203,186,516$ \\
\hline 2014 & $\operatorname{Rp} 19,665,985,816$ & $\operatorname{Rp~} 18,425,580,459$ & $\operatorname{Rp} 19,045,783,138$ \\
\hline
\end{tabular}

Fixed Assets Turnover

\begin{tabular}{|c|c|c|c|}
\hline Tahun & Total Revenue & Average Fixed Assets & $\begin{array}{l}\text { Fixed Assets } \\
\text { Turnover }\end{array}$ \\
\hline 2013 & $\operatorname{Rp} 16,140,873,176$ & Rp 20,203,186,516 & 0.8 \\
\hline 2014 & Rp 15,646,659,894 & Rp 19,045,783,138 & 0.8 \\
\hline
\end{tabular}

Tabel 4 Average Total Assets

\begin{tabular}{|c|c|c|c|}
\hline Tahun & Beginning Total Assets & Ending Total Assets & Average Total Assets \\
\hline 2013 & $\operatorname{Rp} 23,262,991,048$ & Rp 23,136,280,259 & Rp 23,199,635,654 \\
\hline 2014 & Rp $23,136,280,259$ & Rp 23,500,567,633 & $\operatorname{Rp} 23,318,423,946$ \\
\hline \multicolumn{4}{|c|}{ Total Assets Turnover } \\
\hline Tahun & Total Revenue & Average Total Assets & Total Assets Turnover \\
\hline 2013 & Rp $16,140,873,176$ & Rp 23,199,635,654 & 0.7 \\
\hline 2014 & Rp $15,646,659,894$ & Rp 23,318,423,946 & 0.7 \\
\hline
\end{tabular}

\section{Rasio Profitabilitas (Profitability Ratio)}

Berdasarkan tabel 5 dapat diketahui bahwa profit margin atau marjin keuntungan operasional Hotel Ciater Spa \& Resort mengalami kenaikan dari 0,85\% tahun 2013 menjadi $3,07 \%$ di tahun 2014. Kendatipun secara penjualan terus menurun namun marjin keuntungan 
2014 bisa naik, hal ini dikarenakan adanya pengendalian biaya yang cukup berhasil dilakukan oleh manajemen Hotel Ciater Spa \& Resort.

Tabel 5 Rasio Profitabilitas (Profitability Ratio)

\begin{tabular}{|c|c|c|c|}
\hline Tahun & Net Income & Total RevenueProfit & Margin \\
\hline 2013 & Rp 137,547,516 & Rp $16,140,873,176$ & $0.85 \%$ \\
\hline 2014 & $\operatorname{Rp} 480,336,845$ & Rp 15,646,659,894 & $3.07 \%$ \\
\hline \multicolumn{4}{|c|}{ Average Total Assets } \\
\hline Tahun & Beginning Total Assets & Ending Total Assets & Average Total Assets \\
\hline 2013 & Rp 23,262,991,048 & $\operatorname{Rp} 23,136,280,259$ & Rp 23,199,635,654 \\
\hline 2014 & Rp $23,136,280,259$ & Rp 23,500,567,633 & Rp 23,318,423,946 \\
\hline \multicolumn{4}{|c|}{ Return on Assets } \\
\hline Tahun & Net Income & Average Total Assets & Return on Assets \\
\hline 2013 & Rp 137,547,516 & Rp 23,199,635,654 & 0.01 \\
\hline 2014 & Rp 480,336,845 & Rp 23,318,423,946 & 0.02 \\
\hline \multicolumn{4}{|c|}{ Ai-erage Owners'Equity } \\
\hline Tahun & $\begin{array}{c}\text { Beginning } \\
\text { Owner's Equity }\end{array}$ & & \\
\hline & & Owner's Eauitv & Owners' Equitv \\
\hline 2013 & Rp $21,209,299,040$ & Rp 21,346,846,556 & Rp 21,278,072,798 \\
\hline 2014 & Rp 21,346,846,556 & Rp 21,827,183,401 & Rp 21,587,014,979 \\
\hline \multicolumn{4}{|c|}{ Return on Owners' Equity } \\
\hline Tabun & Net Licome & Average & $\begin{array}{c}\text { Return on } \\
\text { Owners Equity }\end{array}$ \\
\hline 2013 & Rp 137,547,516 & Rp 21,278,072,798 & 0.01 \\
\hline 2014 & $\mathrm{Rp} 480,336,845$ & Rp 21,587,014,979 & 0.02 \\
\hline
\end{tabular}

Tingkat pengembalian harta atau return on assets (ROA) tahun 2013 sebesar 0,01 dan mengalami peningkatan menjadi 0,02 pada tahun 2014. Hal ini berarti profit yang dihasilkan oleh manajemen Hotel Ciater Spa \& Resort belum terlalu cukup untuk mempercepat pengembalian asset perusahaan. Demikian pula tingkat pengembalian modal pemilik atau return on owners' equity (ROE) sama dengan return on owners' equity (ROA) yaitu berturlrt-turut 0,01 dan 0,02 untuk tahun 2013 clan 2014 yang berarti kcuntungan dan operasional sclama dua tahun masih jauh untuk menutupi pengembalian modal yang sudah ditanamkan oleh pemilik.

\section{Rasio Operasional (Operating Ratio)}

Berdasarkan tabel 6 terlihat bahwa harga rata-rata kamar (bungalow) cukup tinggi yaitu $\mathrm{Rp}$ 1.113.012.- pada tahun 2013 dan naik menjadi Rp 1.258.578.- pada tahun 2014. Hal ini cukup baik mengingat bahwa Hotel Ciater Spa \& Resort merupakan hotel bintang tiga namun dapat mcncapai harga rata-rata kamar di alas satu juta rupiah. Sedangkan food and beverage percentage menunjukkan bahwa persentase biaya bahan baku makanan dan minuman tinggi pada tahun 2013 dan 2014 yaitu sebesar 40\%. Hal ini mengisyaratkan kepada manajemen Hotel Ciater Spa \& Resort khususnya departemen food \& beverage untuk mengkaji ulang perhitungan recipe costing dan juga penentuan harga jual makanan dan minuman (selling price). 
Adapun labor cost percentage atau persentase tenaga kerja yang ada di Hotel Ciater Spa \& Resort mengalami kenaikan sangat signifikan dari tahun 2013 sebesar 40\% menjadi 50\% pada tahun 2014. Hal ini menunjukkan rasio jumlah karyawan yang terlalu banyak dibandingkan dengan jumlah kamar (bungalow) yang ada sehingga tingkat persentase tenaga kerja dibandingkan dengan pendapatan yang dicapai terlalu tinggi. Pada kebanyakan hotel, tingkat labor percentage rata-rata di bawah $23 \%$ sehingga apa yang terjadi di Hotel Ciater Spa \& Resort terlalu tinggi.

Tabel 6 Rasio Operasional (Operating Ratio)

\begin{tabular}{|c|c|c|c|}
\hline Tabun & Rooms Revenue & Number of Room Sold & $\begin{array}{c}\text { Average Room } \\
\text { Rate }\end{array}$ \\
\hline 2013 & Rp 5,950,163,605 & 5346 & Rp 1,113,012 \\
\hline 2014 & Rp 4,977,676,722 & 3955 & Rp 1,258,578 \\
\hline \multicolumn{4}{|c|}{$F \& B$ Cost Percentage } \\
\hline Tahun & $F \& B$ Cost & F\&B Revenue & $\%$ F\&B Cost \\
\hline 2013 & $\operatorname{Rp} 2,449,321,551$ & Rp 6,174,251,742 & $40 \%$ \\
\hline 2014 & $\operatorname{Rp} 2,113,597,303$ & Rp 5,336,481,757 & $40 \%$ \\
\hline \multicolumn{4}{|c|}{ Labor Cost Percentage } \\
\hline Tahun & Total Labor Cost & Total Revenue & \% Labor Cost \\
\hline 2013 & $\operatorname{Rp} 6,490,632,661$ & Rp 16,140,873,176 & $40 \%$ \\
\hline 2014 & $\operatorname{Rp} 7,802,325,028$ & Rp 15,646,659,894 & $50 \%$ \\
\hline
\end{tabular}

\section{SIMPULAN}

Tingkat likuiditas keuangan Hotel Ciater Spa \& Resort untuk current ratio dan acid-test ratio cukup tinggi yang berarti kemampuan perusahaan khususnya current assets dan quick assets dalam menjamin current liabilities cukup tinggi. Namun demikian perputaran piutang masih terlalu tinggi sehingga akan mengganggu kesehatan cash flow perusahaan di kemudian hari. Sedangkan kemampuan aset perusahaan dalam menjamin hutang (liabilities) perusahaan termasuk tinggi dan meningkat dari tahun ke tahun. Namun demikian bagi pemilik, pemanfaatan hutang baik jangka pendek maupun jangka panjang dalam usaha mempercepat pengembalian investasi perusahaan masih belum maksimal.

Tingkat perputaran persediaan (inventory turnover) Hotel Ciater Spa \& Resort menurun dari 2013 ke tahun 2014 menjadi 9 kali. Hal ini menunjukkan semakin efektifnya pemakaian persediaan yang ada di hotel. Namun demikian untuk perputaran harta tetap fixed asset turnover) dan perputaran total harta (assets turnover) masih belum efektif dalam menghasilkan pendapatan (revenue). Selain itu berdasarkan rasio profitabilitas dapat diketahui bahwa marjin keuntungan yang diperoleh mengalami fluktuasi dengan catatan walaupun penjualan terus menurun dari tahun ke tahun namun manajemen bisa menyikapinya dengan pengendalian biaya yang efektif. Selain itu tingkat pengcmbalian aset (return on assets) dan pengembalian modal pemilik (return on owners 'equity) masih jauh dalam rangka mempercepat pengembalian aset maupun modal pemilik.

Adapun operating ratio khusus di industry bidang jasa atau hospitality bisa diketahui bahwa average room (bungalow) rate yang dicapai oleh Hotel Ciater Spa \& Resort cukup tinggi dibandingkan dengan hotel bintang tiga lainnya karena rata-rata di atas saw juta rupiah. Scdangkan untuk persentasi food and beverage (f\&b) cost enderung naik dari tahun ke tahun. Lebih jauh lagi perhitungan rasio labor percentage yang ada di Hotel Ciater Spa \& Resort saat ini sangat tinggi bahkan terlalu tinggi bila dibandingkan dengan pendapatan yang dicapai. 


\section{DAFTAR REFERENSI}

Abdullah, M. Faisal. 2005. Dasar-Dasar Manajemen Keuangan. UMM Press, Yogyakarta.

Harahap, Sofyan Syafri. 2004. Analisis Kritis Laporan Keuangan. Raja Grafindo Persada. Jakarta.

Ikatan Akuntan Indonesia, 2004. Standar Akuntansi Keuangan (Per 1 Oktober 2004). Salemba Enipat. Jakarta.

Ridwan, S. Sundjaja dan Inge Barlian. 2002. Manajemen Keuangan. PT Prenhallindo. Jakarta.

Sawir Agnes. 2005. Analisis Kinerja Keuangan dan Perencanaan Keuangan. Gramedia Pustaka Utama. Jakarta.

Schmidgall, Raymond S. 2002. Hospitalty Industry Managerial Accounting. Educational Institute of the American Hotel \& Lodging Association. Michigan US.

Suad Husnan dan Enny Pudjiastuti. 2002. Dasar-Dasar Manajemen Keuangan. UPP AMP YKPN. Yogyakarta.

Sugiyono. 2004. Metode Penelitian. Alfabeta. Bandung. 